\title{
Estimated impacts of climate warming on California's high-elevation hydropower
}

\author{
Kaveh Madani • Jay R. Lund
}

Received: 2 September 2008 / Accepted: 22 September 2009 / Published online: 5 November 2009

(C) The Author(s) 2009. This article is published with open access at Springerlink.com

\begin{abstract}
California's hydropower system is composed of high and low elevation power plants. There are more than 150 high-elevation power plants, at elevations above 1,000 feet $(300 \mathrm{~m})$. Most have modest reservoir storage capacities, but supply roughly $74 \%$ of California's in-state hydropower. The expected shift of runoff peak from spring to winter due to climate warming, resulting in snowpack reduction and increased snowmelt, might have important effects on power generation and revenues in California. The large storage capacities at low-elevation power plants provide flexibility to operations of these units under climate warming. However, with climate warming, the adaptability of the high-elevation hydropower system is in question as this system was designed to take advantage of snowpack, a natural reservoir. With so many high-elevation hydropower plants in California, estimation of climate warming effects by conventional simulation or optimization methods would be tedious and expensive. An Energy-Based Hydropower Optimization Model (EBHOM) was developed to facilitate practical climate change and other low-resolution system-wide hydropower studies, based on the historical generation data of 137 high-elevation hydropower plants for which the data were complete for 14 years. Employing recent historical hourly energy prices, the model was used to explore energy generation in California for three climate warming scenarios (dry warming, wet warming, and warming-only) over 14 years, representing a range of hydrologic conditions. The system is sensitive to the quantity and timing of inflows. While dry warming and warming-only climate changes reduce average hydropower revenues, wet warming could increase revenue. Re-operation of available storage and generation capacities help compensate for snowpack losses to some extent. Storage capacity expansion and
\end{abstract}

K. Madani $(\bowtie) \cdot$ J. R. Lund

Department of Civil and Environmental Engineering,

University of California, Davis, CA 95616, USA

e-mail: kmadani@ucdavis.edu

J. R. Lund

e-mail: jrlund@ucdavis.edu 
to a lesser extent generation capacity expansion both increase revenues, although such expansions might not be cost-effective.

\section{Introduction}

Warming is expected over the twenty-first century, with current projections of a global increase of $2^{\circ} \mathrm{F}$ to $11.5^{\circ} \mathrm{F}$ by 2100 (Pew Center on Global Climate Change 2006). The potential effects of climate change on California have been widely discussed from a variety of perspectives (Lettenmaier and Gan 1990; Lettenmaier and Sheer 1991; Aguado et al. 1992; Cayan et al. 1993; Stine 1994; Dettinger and Cayan 1995; Haston and Michaelsen 1997; Gleick and Chalecki 1999; Glieck 2000; Meko et al. 2001; IPCC 2001; Carpenter and Georgakakos 2001; Snyder et al. 2002; Lund et al. 2003; Miller et al. 2003; VanRheenen et al. 2004; Brekke et al. 2004; Dettinger et al. 2004; Zhu et al. 2005; Tanaka et al. 2006; Medellín-Azuara et al. 2008).

Much of California has cool, wet winters and warm, dry summers, and a resulting water supply that is poorly distributed in both time and space (Zhu et al. 2005). On average, $75 \%$ of the annual precipitation of $584 \mathrm{~mm}$ occurs between November and March, while urban, agricultural, and electricity demands are highest during summer and lowest during winter. Spatially, more than $70 \%$ of California's 88 billion cubic meters $(\mathrm{bcm})$ average annual runoff occurs in the northern part of the state (CDWR 1998). Currently, California's large winter snowpack (often considered the largest surface water reservoir in California) melts in the spring and early summer, replenishing water supplies during these drier months. This runoff is used for irrigation, urban supplies, hydropower, and other purposes.

California relies on hydropower for $9 \%$ to $30 \%$ of electricity used in the state, depending on hydrologic conditions, averaging 15\% (Aspen Environmental Group and Cubed 2005). Hydroelectricity's low cost, near-zero emissions, and ability to be dispatched quickly for peak loads are particularly valuable. Temperature changes due to climate change can affect the amount and timing of runoff. Climate warming is expected to reduce accumulated snowpack by melting it sooner and shift some precipitation from snow to rain. Therefore, a shift in the peak flows from late spring and early summer to late winter and early spring is anticipated. Such a shift might hamper California's ability to store water and generate electricity for the spring and summer if available storage capacity is insufficient. The available stream flow from snowmelt or rain can either pass the turbines immediately to generate electricity or be stored in reservoirs to produce hydropower later. The amount of water stored in the reservoir is limited by the available storage capacity. More storage capacity allows more stored water, which leads to less immediate generation and more hydropower generation later when energy prices are greater. Turbine capacity also limits hydropower generation.

Some studies have addressed the effects of climate change on hydropower generation in California, but such analyses have been largely restricted to large lowerelevation water supply reservoirs (Lund et al. 2003; VanRheenen et al. 2004; Tanaka et al. 2006), or a few individual hydropower systems (Vicuña et al. 2008, 2009). There is still a lack of knowledge about the adaptability of California's high-elevation hydropower system to hydrologic changes and global warming effects on statewide 
hydroelectricity generation by largely single-purpose high-elevation hydropower facilities.

\section{California's high-elevation hydropower system}

Current regulators of California hydropower are snowpack and reservoirs. Snowpack is controlled by nature, and reservoirs by man. As temperatures increase, the water stored in snowpack will be released earlier in the year. The vast majority of reservoir storage capacity, over 17 million acre-feet (MAF), lies below 1,000 ft elevation in multipurpose reservoirs, while most in-state hydroelectric capacity is at higher elevations (Aspen Environmental Group and Cubed 2005) and mostly in northern California. Lower elevation storage capacity is used mostly for water storage and flood control, but it also produces a notable amount of hydropower. Roughly $74 \%$ of in-state generated hydropower is supplied by high-elevation units although only about $30 \%$ of in-state usable reservoir capacity is at higher-elevations (Aspen Environmental Group and Cubed 2005).

The high-elevation hydropower system has less manmade storage and may be vulnerable to climate change if storage capacity cannot accommodate a change in runoff volume and timing, as a result of more precipitation in form of rain instead of snow, reduced snowpack, and increased snowmelt in late winter and early spring. Most low elevation hydropower plants (below 1,000 ft) benefit from larger storage capacities and will be affected less than high-elevation hydropower generation (Tanaka et al. 2006). Energy storage and generation capacity limits at high elevation will affect the adaptability of high-elevation hydropower systems. This study investigates the potential effects of climate warming on high-elevation hydropower generation in California and the adaptability of the statewide highelevation system as a result of changes in hydrology by application of the EnergyBased Hydropower Optimization Model (EBHOM) developed by Madani and Lund (2009) for California's high-elevation hydropower system.

\section{Method}

One hundred thirty-seven high-elevation hydropower plants [defined as units located above 1,000 ft (300 m)] in California were identified in this study for which historical monthly generation data were complete for the 14 year 1985 to 1998 period. Studying individual changes in generation patterns as a result of climate change for more than 130 plants by conventional simulation and optimization models would be costly and tedious, especially when basic required information such as stream flows, turbine capacities, storage operating capacities, and energy storage capacity at each reservoir are not readily available for each individual plant. Thus, this study investigates the climate change effects and adaptations through application of the Energy-Based Hydropower Optimization Model (EBHOM) (Madani and Lund 2009), which is based on energy flows and storage instead of water volume balances. EBHOM is a monthlybased optimization model that requires all input variables including monthly runoff, storage capacity, and generation capacity in energy units. Generally, EBHOM can be applied in any hydropower system operation study where there is relatively little 
effect of storage on head and there is an interest in the big picture of the system with details having lesser importance. Madani et al. (2008) found EBHOM reliable for climate change studies by comparing EBHOM against a traditional hydropower optimization model of the Sacramento Municipal Utility District (SMUD) reservoir system (Vicuña et al. 2008). Both models produced similar results when operations of SMUD were modeled under four climate scenarios.

Since runoff patterns vary by elevation, three elevation ranges were considered (1,000-2,000, 2,000-3,000, and above 3,000 ft). Runoff data were obtained for several US Geological Survey (USGS) gauges representing these elevation ranges, selected in consultation with Maury Roos, the former California Department of Water Resources (DWR) chief hydrologist. Monthly runoff distributions were found for each elevation range (Fig. 1). This figure shows the value of snowpack to the system. Runoff peaks later at higher elevations where snowpack is larger and lasts longer. Average historical monthly generation data were perturbed using monthly runoff perturbation ratios of three climate change scenarios, a Dry Warm Scenario (GFDL A2-39), a Wet Warm Scenario (PCM A2-39) (described by Vicuña et al. 2008), and a Warming-Only Scenario. A perturbation ratio is the ratio of flow volume or energy (e.g., average monthly stream flow over the specific period) under a particular scenario (e.g. PCM A2-39) to the corresponding value of the same variable in the same month under baseline (historical) conditions. The perturbation ratios were adjusted for each elevation range. Dry and wet climate warming scenarios result in $20 \%$ less and $10 \%$ more annual runoff at each elevation band, respectively. The warming-only scenario has the historical annual inflow volume, shifting only seasonal timing of flows differently for each elevation band. The ratios were applied to each month of historical runoff to create a climate change hydrology over a multi-year sequence. Figure 2 shows how runoff distributions change for different elevation ranges and climate scenarios. This enables investigation of overall system adaptability and how each hydropower plant might perform over a range of years with climate warming.

The available energy storage capacity at each power plant was estimated based on the No Spill Method (NSM) as explained in Madani and Lund (2009) and tested in Madani et al. (2008). EBHOM was designed for net revenue maximization. In California, most hydropower plants are operated predominantly for net revenue maximization. EBHOM is applicable to systems in which the reservoir is used only for seasonal (as opposed to over-year) hydropower generation. Also, it requires a "high-head" condition where storage does not significantly affect hydropower

Fig. 1 Monthly runoff distributions at different elevation ranges

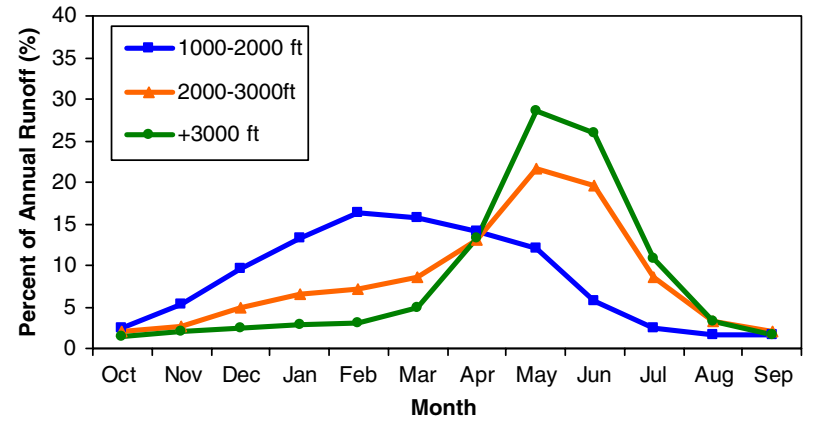


Fig. 2 Monthly runoff distributions for different climate change scenarios and elevation ranges

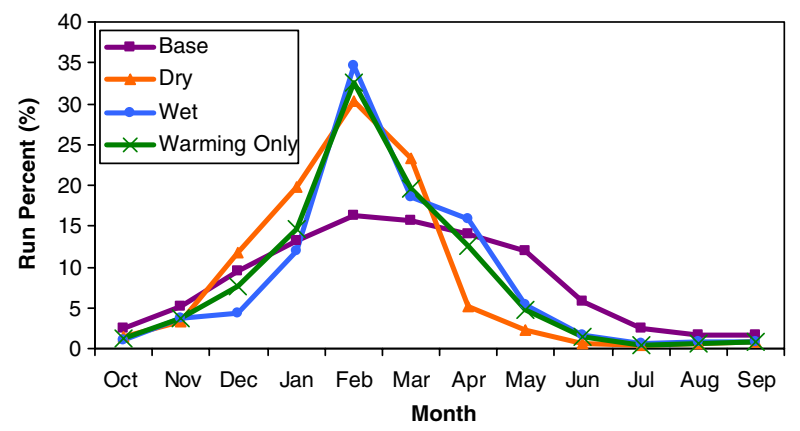

a) $1000-2000 \mathrm{ft}$

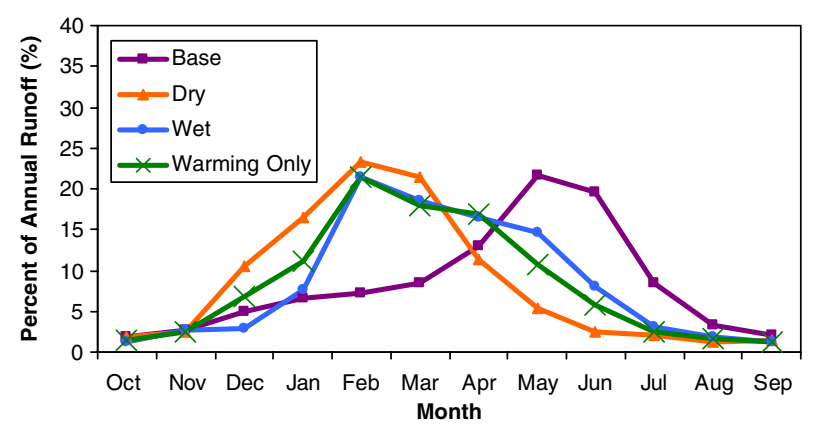

b) $2000-3000 \mathrm{ft}$

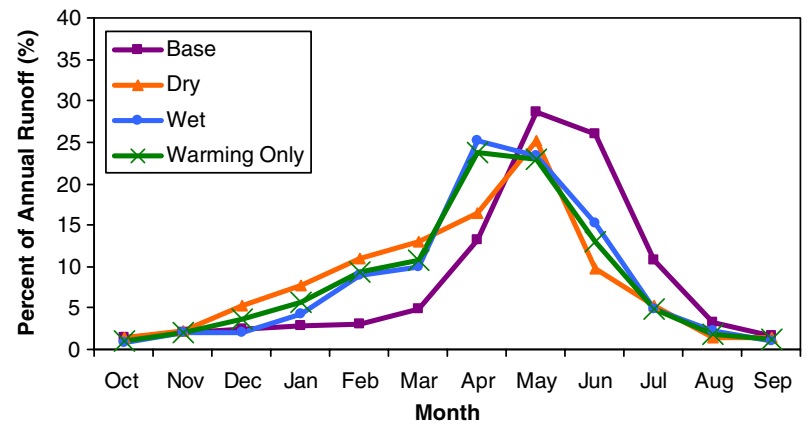

c) $+3000 \mathrm{ft}$

head. EBHOM is solved in Microsoft Excel with "What'sBest", a commercial solver package for Microsoft Excel. EBHOM's formulation can be linear or non-linear. The non-linear EBHOM is solved by linear programming through piecewise linearization of the concave revenue function (Madani and Lund 2009). Linear EBHOM (Madani and Lund 2007) does not capture the effects of off-peak and on-peak energy prices on operations well. The non-linear EBHOM was used here with off-peak and on-peak energy prices captured using a method that considers the non-linear relationship between monthly generation and monthly revenue based on recorded hourly prices (Madani and Lund 2009). Real time hourly hydroelectricity prices for 2005-2008 (California ISO OASIS 2009) were used in this study, as such data were only available for this period at the time of this study. Real time hourly data are useful 
for incorporating on-peak and off-peak hydropower prices. Therefore, using the real time data set which does not match the modeling period was preferred to application of average monthly prices which result in failure to capture the effects of on-peak and off-peak pricing.

EBHOM is a deterministic optimization model. Therefore instead of using rule curves for reservoir operations, as done in simulation models, EBHOM finds operations which yield the highest possible revenue for the known inflows in a given year, subject to energy storage and capacity constraints which are constant over the modeling period. EBHOM uses a unique method for reflecting the non-linear relationship between the average monthly hydropower price and the hours of turbine usage in that month, based on the historical real-time hourly price set incorporated in the model. The average hydropower price in each month is determined based on the proportion of generation capacity used in that month while marginal benefit of used generation capacity decreases with increase in the used proportion of turbine capacity. Therefore, prices can vary from month to month and also between the same months in different years, based on the proportion of generation capacity used (Madani and Lund 2009).

For each year from 1985 to 1988, EBHOM was run to estimate optimal monthly reservoir storage and energy generation decisions for each of the 137 power plants. The model was run for four climate scenarios, including the base case (Historical) hydrology and three climate change hydrologies (Dry Warming, Wet Warming, and Warming-Only). Since the model optimizes decisions one year at a time, 14 years of results were used to model variations in performance over the 1985 to 1998 period. Assuming no over-year storage, release decisions in each year are independent. Figure 3 (from Madani and Lund 2009) indicates the range of estimated energy storage and generation capacities of the 137 studied high-elevation hydropower plants. The annual energy storage capacities of most of the studied high-elevation hydropower plants are at least 1.5 times larger than their monthly generation capacity, providing some operational flexibility. For more than 100 of these power plants, active storage capacity exceeds one month of generation capacity (Madani and Lund 2009).

\section{Results}

Table 1 indicates how energy generation, energy spill and annual revenue change with climate scenarios. Revenue is greatest for the Wet-warm scenario and least for

Fig. 3 Range of the estimated energy storage and generation capacities of the 137 studied high-elevation hydropower plants in California (adopted from Madani and Lund 2009)

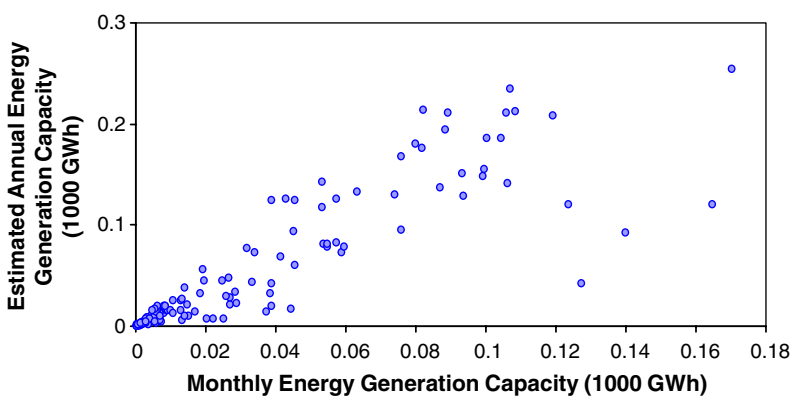


Table 1 EBHOM's results (average of results over 1985-1988 period) for different climate scenarios

\begin{tabular}{lllll}
\hline & Base & Dry & Wet & Warming-only \\
\hline Generation (1,000 GWH/year) & 22.3 & 17.9 & 23.6 & 22.0 \\
Generation change with respect to the base case (\%) & & -19.7 & +5.8 & -1.3 \\
Spill (MWH/year) & 130 & 96 & 1,112 & 735 \\
Spill change with respect to the base case (\%) & & -26 & +755 & +255 \\
Revenue (million \$/year) & 1,791 & 1,536 & 1,822 & 1,754 \\
Revenue change with respect to the base case (\%) & & -14.2 & +1.7 & -2.1 \\
\hline
\end{tabular}

the Dry-warm scenario. Although annual inflow is $10 \%$ higher than the Base case for the Wet scenario, revenue is only about $2 \%$ higher than the Base scenario when optimized operations are applied. This is due to storage capacity limits, the system being designed to take advantage of historical snowpack, and monthly energy prices following the historical pattern. Although generation is almost $6 \%$ higher under the Wet scenario, revenue is only $2 \%$ higher. Energy spill is greatest under the Wet scenario due to limited storage and generation capacities.

While total annual inflow does not change for the Warming-Only scenario (shifting only runoff timing), total revenue is reduced by $2 \%$ due to limited storage capacity and some limited generation capacity, and spills greatly increase over the Base case. The timing of snowmelt and the form of precipitation (as snow or rain), in addition to total runoff volume, affect generation patterns, total generation, and power values. When reservoir capacity cannot store the peak flow from snowpack melt for release in high-value months, revenues are reduced as a result of energy spill or generation in months when energy prices are not the highest. However, some storage capacity is available to handle the extra winter runoff under a warmer climate. This provides some flexibility in operations to store winter water to be released when energy demand is higher. As a result, although annual inflow under the Dry scenario is $20 \%$ less than in the Base case, Dry scenario revenues are reduced by more than $14 \%$ even though energy generation reduction under this scenario exceeds $19 \%$. Energy spills under this scenario increase relative to the Base case during peak runoff months, causing some off-peak generation losses.

\subsection{Generation changes with climate warming}

Figure 4 shows average monthly energy generation for 1985 to 1998 hydrologic conditions, modified for different climate changes. Results are summed from all 137

Fig. 4 Average monthly generation (1985-1998) under different climate scenarios

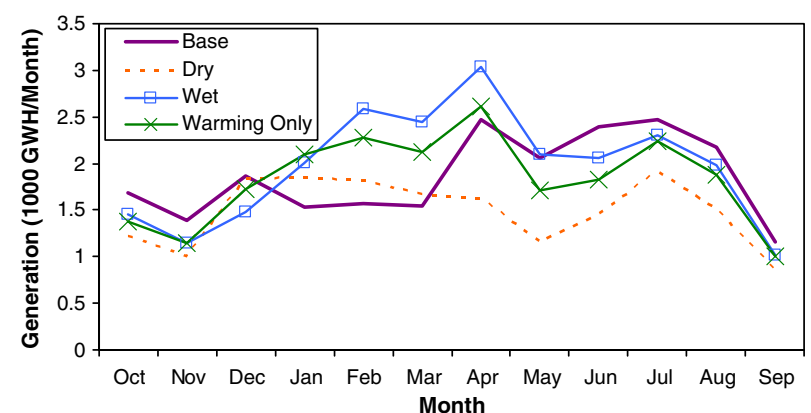


power plants modeled in this study. Generally, model results suggest less generation in months with lower average energy prices to keep the reservoir storage higher for generation in later months with higher energy prices. Summer generation is less than the Base case for all three climate warming scenarios. Generation under the climate warming scenarios can be higher than the Base case during the January-April period due to increased runoff peaks and limited capacity to store the shift in peak runoff. In the rest of the year, generation under climate change is always less than the base generation, but with almost the same trend which mostly follows the energy price pattern. If more storage capacity were available, there would be less likelihood of water bypassing turbines ("spills") from January to April. Instead, this water would be stored and released in summer, reducing generation in late winter and early spring to increase summer generation (when prices are higher).

Figure 5 shows the frequency of optimized monthly generation for each month over the 14 year period (1985-1998) summed for all units, for the different climates. Dry climate warming always has considerably less generation than Base generation over the 14 year period. Under the Wet climate generation exceeds the Base case $85 \%$ of the time. However, in $65 \%$ of months, the difference is small. Generation with the Warming-Only scenario is less than the Base case in $60 \%$ of months. It differs only slightly from the Base generation in $65 \%$ of months. Generation is considerably less than the Base generation in $25 \%$ of months (summer months), and higher in $10 \%$ of months (late winter-early spring months). If more storage capacity were available, generation frequency curves under Wet and Warming-Only scenarios could be closer to the Base scenario, with higher revenues. Generation curves under Wet and Warming-Only scenarios exceed the Base case when storage capacity cannot store more winter flows for summer and spring generation, forcing operators to release up to the turbine capacity or spill excess flows as reservoirs fill in January to April.

\subsection{Reservoir storage changes with climate warming}

Figure 6 shows how average end-of-month energy storage in all reservoirs combined changes with climate when reservoirs are operated for energy revenues only. Under the Base scenario, reservoirs reach their minimum storage by the end of December to prepare to capture expected inflow from winter precipitation and later spring snowmelt. On average, reservoirs fill by June and gradually empty for energy generation over the summer when energy prices are higher and there is little natural

Fig. 5 Frequency of optimized monthly generation (1985-1998) under various climate scenarios (all months, all years, all units)

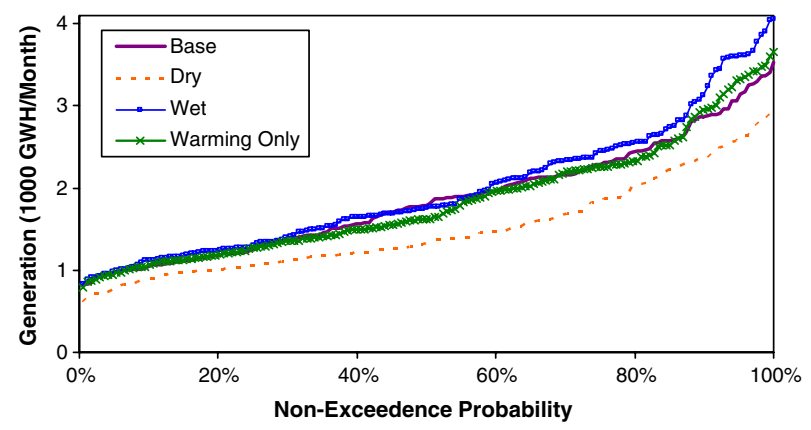


Fig. 6 Average total endof-month energy storage (1985-1998) under different climate scenarios

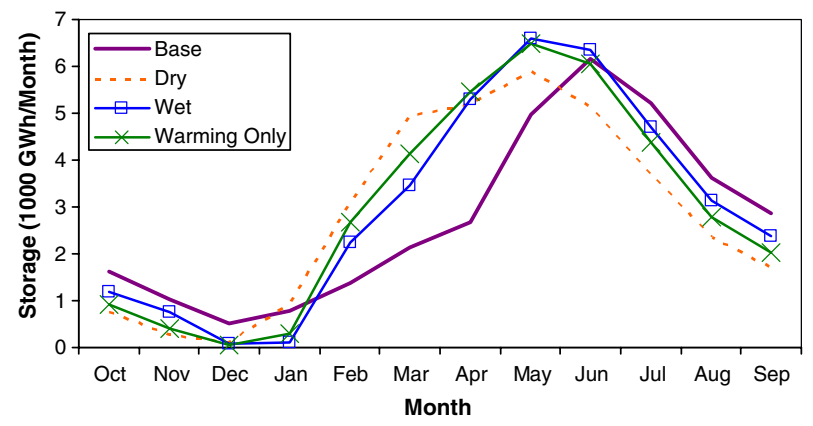

inflow. Under historical conditions, refill starts in January and drawdown starts in June. Although climate warming results do not appear to change the start of the refill season, energy storage peaks earlier and drawdown begins a month earlier due to earlier snowmelt. Climate change generally increases average reservoir storage (stored energy) between February and May due to snowpack loss.

\subsection{Energy spills with climate warming}

Figure 7 shows the frequency of total monthly energy spill from the system for the study period when the system is optimized for revenue maximization. Energy spill results from runoff that can be neither stored nor sent through turbines because of limited capacities. Energy spill is the equivalent energy value of the available runoff water which cannot contribute to energy production at each site. Energy is spilled by the system in 35\% and 30\% of months under the Wet and Warming-Only scenarios, respectively. Energy spill does not occur more than $20 \%$ of the time, under the Base and Dry scenarios. The magnitude of spills also increases for Wet and WarmingOnly scenarios. With the Dry scenario, the magnitude of spill decreases in $14 \%$ of the months. Existing storage capacity cannot compensate for the loss of snowpack during wetter years and overall earlier snow melt, but appears able to compensate in drier years.

What is calculated as energy spill in this study is the increased energy spill, with respect to the Base case. Since annual historical generation (actual recorded output of the system) in each year during 1985 to 1994 period was used as the annual energy input to calibrate the hydropower system model, zero spill under the Base

Fig. 7 Frequency of total monthly energy spill (1985-1998) under different climate scenarios (all months, all years, all units)

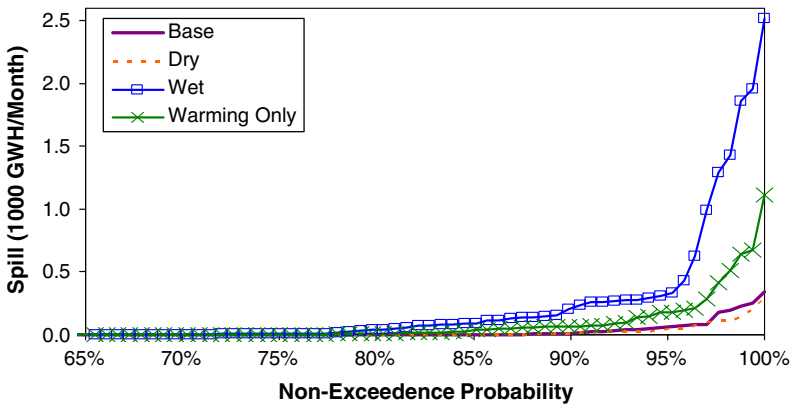


Fig. 8 Average monthly total energy spill (1985-1998) under different climate scenarios

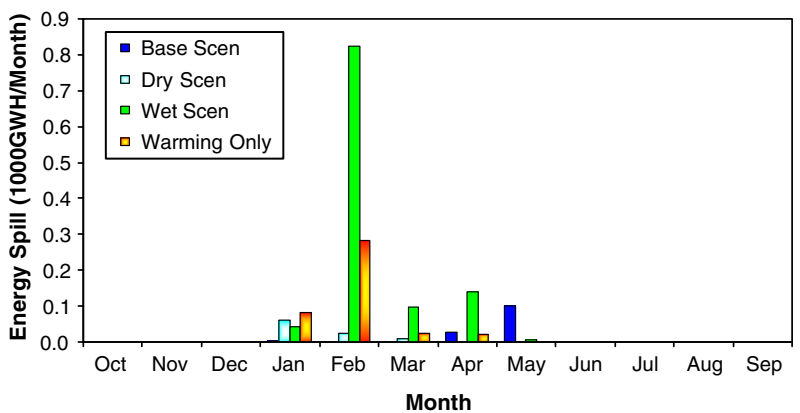

case was expected. However, the results showed a minimal error ( 0.6 percent of total generation on average) in calculation of energy spills under the historical scenario.

Figure 8 shows the distribution of total average monthly energy spill for different climates. Under the historical climate, energy spills occur from January to May when inflow to the system peaks. Monthly energy spill peaks in May under this scenario and can be as high as $100 \mathrm{GWh}$ on average. Climate warming generally increases spills above the Base case in months with low hydropower prices. Energy spills are expected from January to May under climate warming. Most energy spills occur in January with the Dry climate and in February with the Wet and WarmingOnly climates. The average monthly energy spill can be as high as $60 \mathrm{GW}$ for the Dry scenario and 800 and $300 \mathrm{GWh}$ under the Wet and Warming-Only scenarios, respectively. The changes in the magnitude and timing of spills under different climate warming scenarios indicate the relative importance of runoff inflow timing and magnitude to the performance of this system.

Figure 9 plots the frequency curve of total annual spill from the system for the study period. Energy spill under the Base scenario is not substantial for $60 \%$ of the years. Annual energy spill frequency and magnitude both increase with Wet and Warming-Only scenarios and decrease with Dry warming. Most energy spill occurs with the Wet scenario, in more than $80 \%$ of years. Under the Warming-Only and Dry scenarios, energy spills are significant in more than $60 \%$ and $30 \%$ of years, respectively.

Fig. 9 Frequency of total annual energy spill (1985-1998) under different climate scenarios (all years, all units)

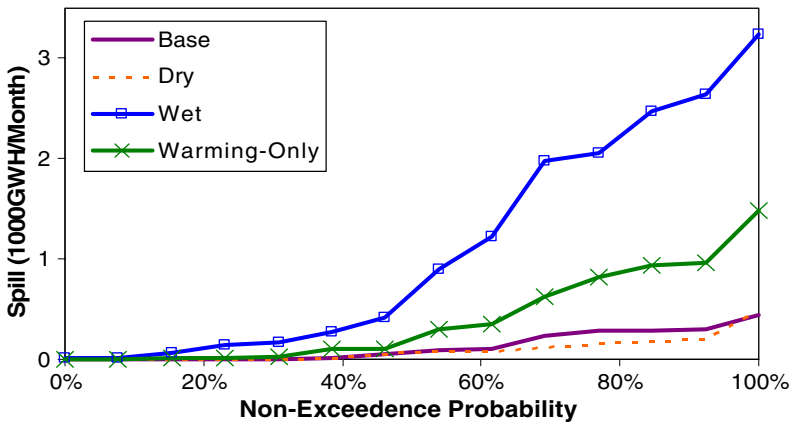


Fig. 10 Frequency of monthly energy price (1985-1998) under different climate warming scenarios (all months, all years, all units)

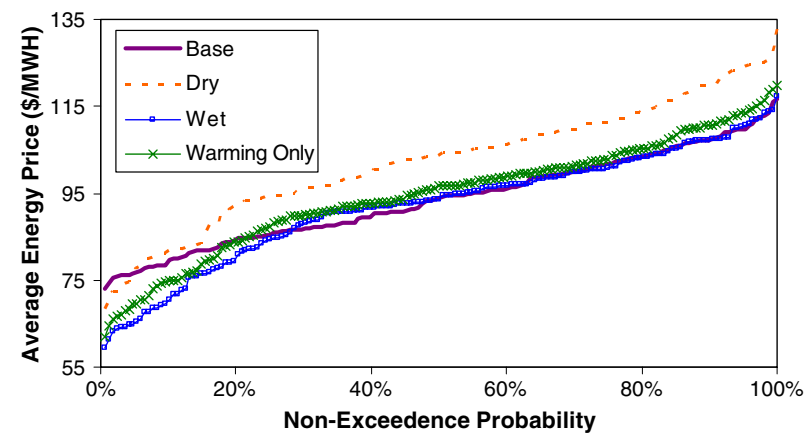

\subsection{Revenue and energy price patterns under climate warming}

Figure 10 indicates climate warming effects on monthly average price received for generated energy. Climate warming generally increases average hydropower prices at least in more than $70 \%$ of months, as generation with climate warming is less than base generation in most of the year, especially in high-value months. Energy prices under the Wet scenario are the same as the Base case prices in almost half of months. As expected, the rise in prices received is highest with Dry climate warming (given the non-linear relationship between electricity price and generation quantity). Under this scenario prices are higher than the Base case more than $95 \%$ of the time. Average received energy price frequency curves for Wet and WarmingOnly scenarios show similar behavior, with higher prices under the Warming-Only scenario, highlighting the importance of runoff timing over quantity for optimal system operations.

Figure 11 shows the effects of climate warming on the frequency of total annual revenues from all 137 hydropower plants studied for the period 1985 to 1998. Although monthly average prices received for generated energy were higher under the Dry scenario, the increase in average prices received does not compensate for the Dry scenario reduction in energy generation. On average, annual revenues are $\$ 255$ million lower than the Base case for the Dry scenario. Annual revenue under the Wet scenario exceeds Base scenario revenue in $70 \%$ of years due to increased annual generation. However, the maximum annual revenue is obtained under the Base scenario, highlighting the importance of timing of inflows rather than just their quantity. For the same reason (changed timing of inflows), annual revenue

Fig. 11 Frequency of total annual revenue (1985-1998) under different climate scenarios (all years, all units)

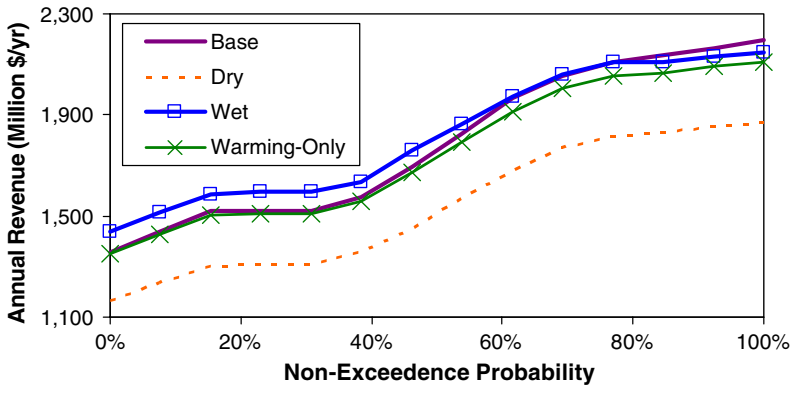


for the Warming-Only scenario is always less than the Base case. Nevertheless, the difference is insignificant in $40 \%$ of years.

In this study, the effects of climate warming on energy demand were neglected. To improve the estimations, in future, the effects of climate change on energy demand can be studied by defining different relationships between energy generation quantity and energy price for various scenarios (Madani and Lund 2009).

\subsection{Benefits of expanding energy storage and generation capacity}

Figure 12 shows, on average, how energy storage capacity expansion changes hydropower generation revenues for different climate scenarios over the study period (14 years). This figure indicates the average shadow price of energy storage capacity (the increase in annual revenue per $1 \mathrm{MWh}$ energy storage capacity expansion) for all 137 reservoirs. For instance, increase in annual revenue per $1 \mathrm{MWh}$ energy storage capacity expansion is less than $\$ 35, \$ 47, \$ 54$, and $\$ 55$ for all the studied power plants (137 units) under the Base, Dry, Wet, and Warming-Only scenarios. Storage capacity expansion reduces spills and allows for more release in summer when energy prices are higher. Storage capacity expansion can increase average annual revenues for almost all hydropower plants under all climate scenarios (except for eight power plants under the Dry scenario), altough such expansion might not be justified due to expansion costs. As expected, benefits of capacity expansion are greater for Wet and Warming-Only scenarios when the additional capacity can be more frequently used. The annual marginal benefit of storage capacity expansion is greatest for the Wet scenario when more energy is available to store. Even with the historical hydrology, expanding storage capacity increases total annual revenues in all years because more storage capacity allows shifting generation to higher price times.

Figure 13 indicates the average shadow price of energy generation (turbine) capacity (increase in annual revenue per $1 \mathrm{MWh}$ of annual energy generation capacity expansion) for all 137 plants under different climate scenarios. Similar to storage capacity expansion, energy capacity expansion can increase average annual revenues for all hydropower plants under all climate scenarios. Although generation capacity expansion does not provide substantial flexibility in operations, it can reduce energy spill. Energy generation capacity is most valuable for Wet climate warming when energy spills are highest and least valuable under Dry climate warming when energy spills are least. Under a Warming-Only climate, energy generation capacity expansion value is slightly more than the base case. Even though generation capacity expansion produces benefits, expansion costs might be prohibitive.

Fig. 12 Average shadow price of energy storage capacity of 137 hydropower units in California in the 1985-1998 period under different climate scenarios

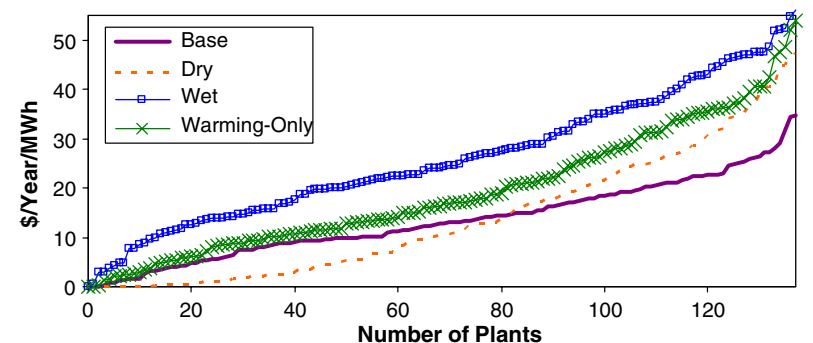


Fig. 13 Average shadow price of energy generation capacity of 137 hydropower units in California in the 1985-1998 period under different climate scenarios

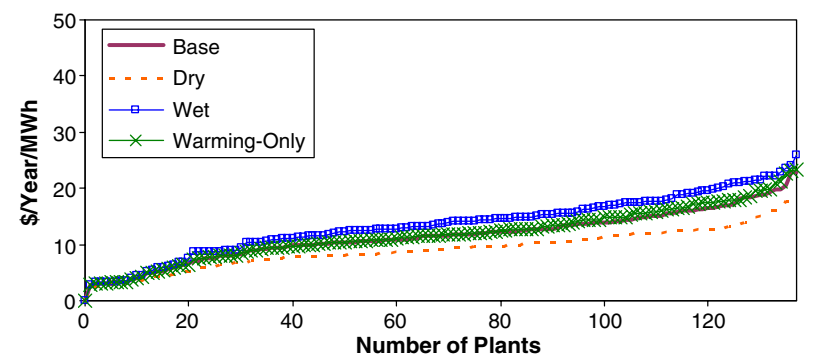

Comparison of Figs. 12 and 13 shows that energy storage capacity expansion is typically more beneficial than energy generation capacity expansion if the expansion costs are the same. Figure 14 clarifies that by indicating how the marginal benefits of energy storage and generation capacity expansion of power plants vary with climate. This figure also indicates the relative importance of extra energy generation and storage capacity for each unit and how that may vary with climate warming. Each point in the figure represents a powerplant. The coordinates of each point are the energy generation and storage capacity shadow prices. For the base scenario 78 power

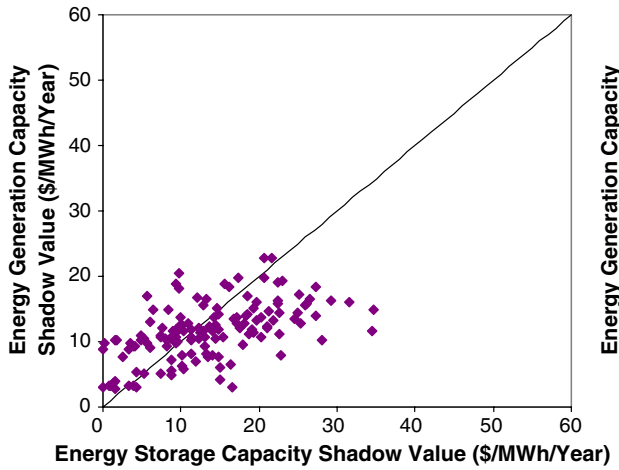

a) Base

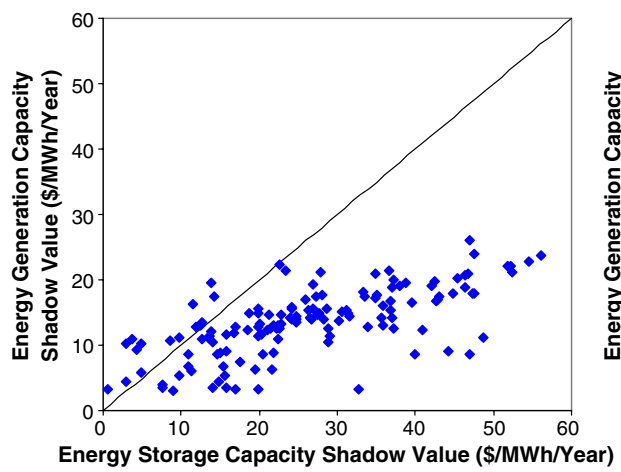

c) Wet

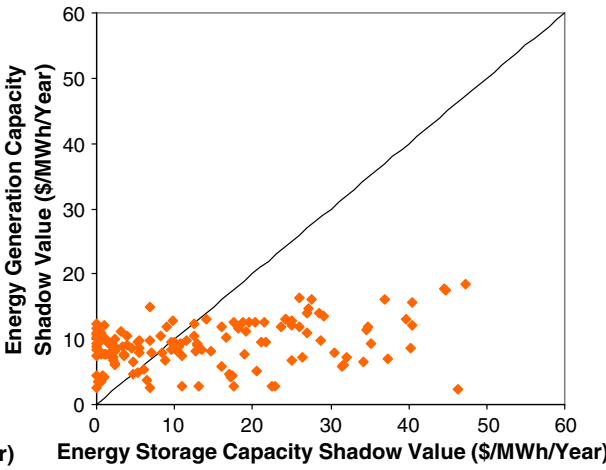

b) Dry

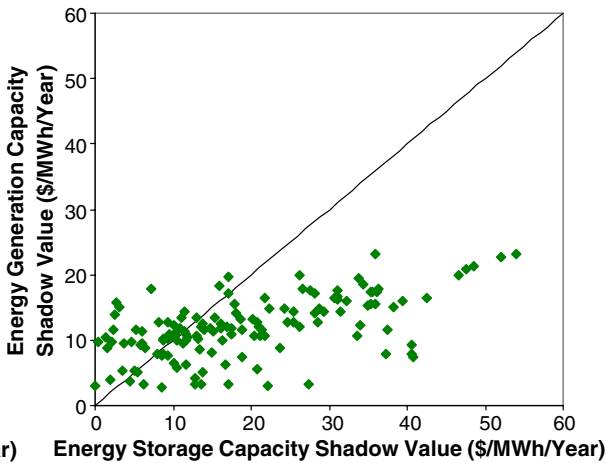

d) Warming-Only

Fig. 14 Average shadow values of energy storage and generation capacity of 137 hydropower units in California in the 1985-1998 period under different climate scenarios 
plants benefit more from energy storage capacity expansion than energy generation expansion. On average, the marginal benefit of energy storage capacity expansion is 1.20 times larger than the benefit of energy generation capacity expansion for all power plants under this scenario. Although, energy storage capacity expansion is not beneficial for eight power plants under the Dry scenario, 79 power plants benefit more from storage than energy generation capacity expansion. Comparison of Fig. 14a with Fig. 14b-d shows how storage capacity becomes more valuable under climate warming as the scatter in the figures expands to the right, highlighting the higher benefit from energy storage capacity expansion than generation capacity expansion. Energy storage capacity shadow price is 1.72, 2.07, and 1.74 times higher than the energy generation shadow price for all power plants under the Dry, Wet, and Warming-Only scenarios. The number of power plants benefiting more from storage capacity expansion than generation capacity expansion reaches 122 and 101 under the Wet and Warming-Only scenarios. Under climate change, while the marginal benefit of energy generation capacity expansion almost never exceeds $\$ 25$ under climate change, marginal benefit of energy storage capacity expansion can exceed $\$ 55$.

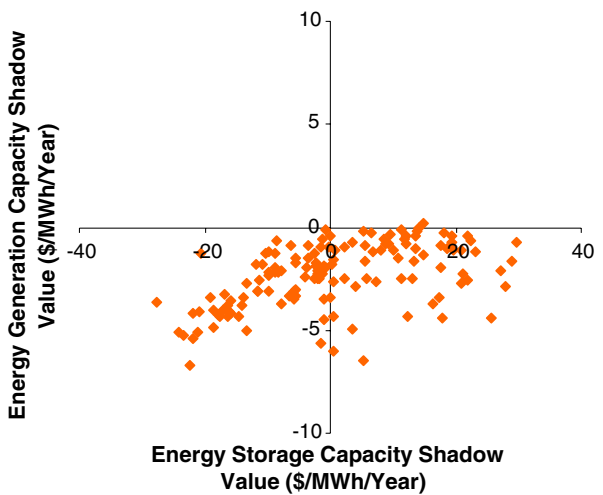

a) Dry

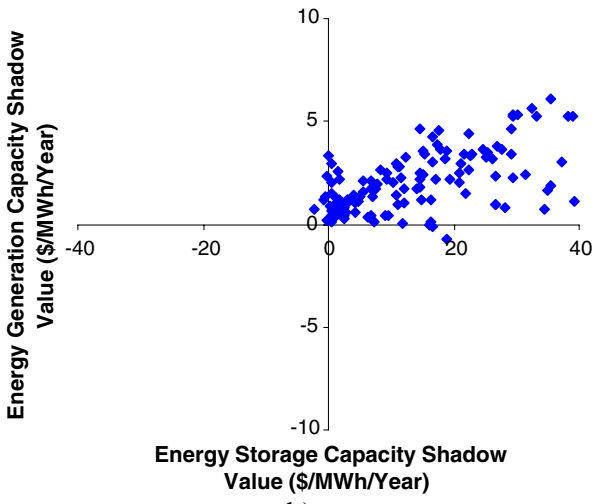

b) Wet

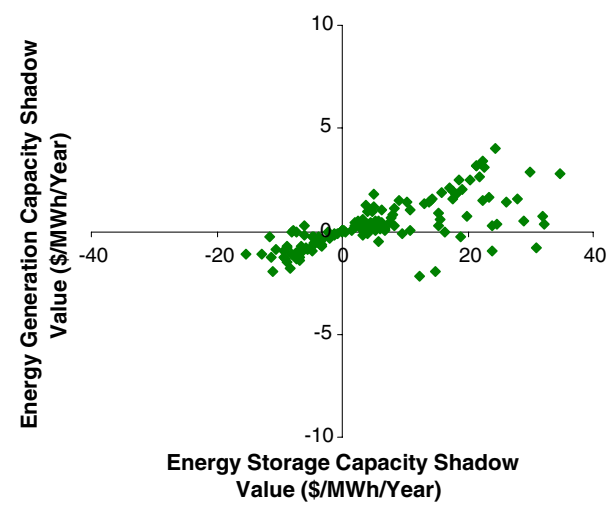

c) Warning-Only

Fig. 15 Average change of energy storage and generation capacity shadow values from the base case with different climate scenarios (for 137 hydropower units in California in the 1985-1998 period) 
Figure 15 shows the changes of marginal benefit of energy storage and generation (turbine) capacities relative to the Base (Fig. 14a) case with different climate warming scenarios. Under the Dry scenario, marginal benefits of energy generation capacity of all units are lower than the Base case. There is less inflow, so the existing storage and generation capacities are more often sufficient to avoid spills. For about $62(45 \%)$ of plants, the value of expanding energy storage under drier conditions is more than with the Base case, allowing more winter inflows to be shifted to highvalue summer power generation (the maximum difference can be as high as \$30). For the Wet scenario almost all units benefit from energy storage and generation capacity expansions, resulting in more generation in high-energy value months and less spills. For most units, expanding energy storage capacities is more valuable than increasing energy generation capacities with this scenario. With the Warming-Only climate, 76 units (55\% of all units) benefit more from expanding both energy storage and generation capacities than in the base case, highlighting the importance of inflow timing for the existing system with limited storage and generation capacities.

\section{Limitations}

Models are not perfect and optimized results are optimized to particular conditions and objectives. During model development many simplifying assumptions are made which should be considered in interpreting results. However, simulation and optimization models are useful in studying resource management problems. Here, results give some insights on how the system works and how it might adapt under different climate warming scenarios.

Calibration of EBHOM for this study is likely to under-estimate energy storage capacities (Madani and Lund 2009) and therefore also underestimate adaptability of the system to climate changes. Availability of spill or energy storage capacity data would reduce this source of error.

California is big and variable in hydrology. Assuming the same seasonal pattern for inflows in north and south at the same elevation will cause some inaccuracies. A $1,000 \mathrm{ft}$ range covers a great variability in hydrology. Smaller elevation ranges might increase the accuracy of the estimation. Since many power plants are in the 3,0004,000 ft elevation range, it might be worthwhile to study this range separately. More gauges also might be considered for each elevation range.

As a first step in studying the adaptability of California's high-elevation hydropower system to climate warming, this study looks at flexibility of operations without considering environmental constraints.

Here, energy prices were imposed on each individual power plant. Instead, total demands might be imposed to the system of 137 plants. This gives more flexibility in operation and reaction of the system. High-elevation plants at lower elevations which receive peak flows earlier and generate more in earlier months while higher plants generate more later in the year. Although the timing of flow will change, there is still a difference in flow patterns at different elevation ranges which benefits the system if operated wisely. By integrating operations of individual hydropower systems that span different watersheds and elevation bands, greater operational flexibility to respond to changes in climate, streamflow, and runoff may be possible. 
With climate warming energy demands and prices are likely to increase in warmer months from higher temperatures. EBHOM employed recorded real-time energy prices for finding revenue curves which define the relation between monthly energy generation and energy price. The prices used here are from 2005-2008 which do not exactly match energy prices of the 1985 to 1998. This might cause some inaccuracies in EBHOM's estimation of revenues and energy prices. However, this limitation might not affect other results (generation, spill, and storage) much as the energy price trends are similar between years. Application of longer-period price data sets in future might improve the accuracy of model results.

For this application it was assumed inflow distributions adhere to a fixed seasonal pattern. Inflow distributions are likely to be more local and vary more between years. Here, the model optimizes revenue based on its perfect information about the year's hydrological pattern. Such management is impossible in practice.

\section{Conclusions}

In absence of detailed information about the available energy storage capacity at high-elevation in California, this study applied a simple low-resolution approach for estimating the adaptability of California's high-elevation hydropower generation to climate warming. Substituting the estimated energy content of runoff water inflows and storage for these relatively high-head hydropower units and estimating seasonal inflow distribution patterns by elevation band allowed preliminary optimizationdriven monthly system operations modeling of more than 137 hydropower plants with various climate changes.

With climate warming, California loses snowpack that has functioned historically as a seasonal reservoir to delay runoff, but considerable energy storage and generation capacities remain available. The EBHOM's results show that most extra runoff in winter from climate warming can be accommodated by the available storage capacity at high-elevation sites for average years. Lower-elevation reservoirs, constructed primarily for water supply, already have substantial re-regulation capacity for seasonal flow adjustments (Tanaka et al. 2006) and operating rules should change with climate warming to adapt to changes in hydrology (Medellín-Azuara et al. 2008).

Generally, climate warming alone, without changes in total runoff, reduces highelevation hydropower generation and revenue, due solely to changes in seasonal runoff timing which increase energy spill from the system due to limited energy storage and generation capacities. Energy spills increase dramatically under Wet and Warming-Only scenarios with existing storage and generation capacities. More storage capacity would increase revenues but might not be cost effective. Storing water in reservoirs helps shift energy runoff reductions to months with lower energy prices to reduce economic losses. More generation capacity also increases revenues by reducing energy spill. Annual marginal benefits of capacity expansion are higher for storage than for generation. Nevertheless, current storage and generation capacities give the system some flexibility to adapt to climate change. Although the Dry scenario examined in this study has $20 \%$ less runoff than the base historical hydrology, system-wide, revenues decrease by less than $14 \%$ through optimally re-operating storage and generation facilities within existing capacities. Thus, current storage and generation capacities can compensate for some snowpack loss. 
Limited capacities cannot take full advantage of increased energy runoff under the Wet scenario. The Wet warming scenario examined here has $10 \%$ more runoff than the historical hydrology, but only $6 \%$ more generation and $2 \%$ more average annual revenues. In a Warming-Only scenario with unchanged historical precipitation, generation and revenues decrease by 1 and almost $2 \%$, respectively.

This study required some simplifying assumptions. Nevertheless, it gives insights and suggests some degree of adaptive capability to climate warming. Future studies should address environmental and other constraints, include demand and price impacts of climate change, and apply refined estimates of varied hydrologic changes from climate change across California.

Acknowledgements The authors thank Omid Rouhani from University of California, Davis for his help in EBHOM development, Maury Roos from California Department of Water Recourses for providing the names of reliable high-elevation gauges in California, Peter Gleick and Christina Connell, from Pacific Institute and University of California, Davis, respectively, for their editorial comments and suggestions, Jason Bartlett from University of California, Berkeley for assistance with revision of the historical hydropower generation database, and Jery Stedinger from Cornell University for his early feed-back on the work. This work was funded by the California Energy Commission's Public Interest Energy Research (PIER) program and the Resources Legacy Fund Foundation.

Open Access This article is distributed under the terms of the Creative Commons Attribution Noncommercial License which permits any noncommercial use, distribution, and reproduction in any medium, provided the original author(s) and source are credited.

\section{References}

Aguado E, Cayan D, Riddle L, Roos M (1992) Climate fluctuations and the timing of west coast streamflow. J Climate 5:1468-1483

Aspen Environmental Group, Cubed M (2005) Potential changes in hydropower production from global climate change in California and the western United States. California Climate Change Center, CEC-700-2005-010, June 2005 (http://www.energy.ca.gov/2005publications/CEC-7002005-010/CEC-700-2005-010.PDF)

Brekke LD, Miller NL, Bashford KE, Quinn NWT, Dracup JA (2004) Climate change impacts uncertainty for water resources in the San Joaquin River Basin, California. J Am Water Resour Assoc 40(1):149-164

California ISO OASIS (2009) Hourly average energy prices. California Independent System Operator (ISO) Open Access Same-Time Information System (OASIS). http://oasis.caiso.com/. Accessed May 2009

Carpenter TM, Georgakakos KP (2001) Assessment of Folsom lake response to historical and potential future climate scenarios: 1. Forecasting. J Hydrol 249:148-175

Cayan DR, Riddle LG, Aguado E (1993) The influence of precipitation and temperature on seasonal streamflow in California. Water Resour Res 29(4):1127-1140

CDWR (California Department of Water Resources) (1998) The California water plan update; bulletin, vol 1. California Department of Water Resources, Sacramento, pp 160-198

Dettinger MD, Cayan DR (1995) Large-scale atmospheric forcing of recent trends toward early snowmelt runoff in California. J Climate 8(3):606-623

Dettinger MD, Cayan DR, Meyer MK, Jeton AE (2004) Simulated hydrologic responses to climate variations and change in the Merced, Carson, and American River Basins, Sierra Nevada, California, 1900-2099. Clim Change 62:283-317

Gleick PH, Chalecki EL (1999) The impact of climatic changes for water resources of the Colorado and Sacramento-San Joaquin river systems. J Am Water Resour Assoc 35(6):1429-1441

Glieck PH (2000) The report of the water sector assessment team of the National Assessment of the Potential Consequences of Climate Variability and Change. Pacific Institute for Studies in Development, Environment, and Security, Oakland, California 
Haston L, Michaelsen J (1997) Spatial and temporal variability of Southern California precipitation over the last $400 \mathrm{yr}$ and relationships to atmospheric circulation patterns. J Climate 10(8): $1836-1852$

IPCC (Intergovernmental Panel on Climate Change) (2001) Climate change 2001: the scientific basis. Cambridge University Press, Cambridge, $881 \mathrm{pp}$

Lettenmaier DP, Gan TY (1990) Hydrologic sensitivity of the Sacramento-San Joaquin River Basin, California, to global warming. Water Resour Res 26(1):69-86

Lettenmaier DP, Sheer DP (1991) Climatic sensitivity of California water resources. J Water Resour Plan Manage 117(1):108-125

Lund JR, Zhu T, Jenkins MW, Tanaka S, Pulido M, Taubert M, Ritzema R, Ferriera I (2003) Climate warming \& California's water future. Appendix VII, California Energy Commission: Sacramento, pp 1-251. http://www.energy.ca.gov/reports/2003-10-31_500-03-058CF_A07.PDF

Madani K, Lund JR (2007) Aggregated modeling alternatives for modeling California's highelevation hydropower with climate change in the absence of storage capacity data. Hydrol Sci Technol 23(1-4):137-146

Madani K, Lund JR (2009) Modeling California's high-elevation hydropower systems in energy units. Water Resour Res 45:W09413. doi:10.1029/2008WR007206

Madani K, Vicuna S, Lund J, Dracup J, Dale L (2008) Different approaches to study the adaptability of high-elevation hydropower systems to climate change: the case of SMUD's upper american river project. In: Babcock RW, Walton R (eds) Proceeding of the 2008 world environmental and water resources congress, Honolulu, Hawaii. ASCE

Medellín-Azuara J, Harou JJ, Olivares MA, Madani K, Lund JR, Howitt RE, Tanaka SK, Jenkins MW, Zhu T (2008) Adaptability and adaptations of California's water supply system to dry climate warming. Clim Change 87(Suppl 1):S75-S90

Meko DM, Therrell MD, Baisan CH, Hughes MK (2001) Sacramento river flow reconstructed to A.D. 869 from tree rings. J Water Resour Plan Manage (JAWRA) 37(4):1029-1039

Miller NL, Bashford KE, Strem E (2003) Potential impacts of climate change on California hydrology. J Water Resour Plan Manage 39(4):771-784

Pew Center on Global Climate Change (2006) www.pewclimate.org/global-warming-basics/about

Snyder MA, Bell JL, Sloan LC, Duffy PB, Govindasamy B (2002) Climate responses to a doubling of atmospheric carbon dioxide for a climatically vulnerable region. Geophys Res Lett 29(11):L04806. doi:10.1029/2001GL014431

Stine S (1994) Extreme and persistent drought in California and Patagonia during medieval time. Nature 369:546-549

Tanaka ST, Zhu T, Lund JR, Howitt RE, Jenkins MW, Pulido MA, Tauber M, Ritzema RS, Ferreira IC (2006) Climate warming and water management adaptation for California. Clim Change 76(34):361-387

VanRheenen NT, Wood AW, Palmer RN, Lettenmaier DP (2004) Potential implications of PCM climate change scenarios for Sacramento-San Joaquin River Basin hydrology and water resources. Clim Change 62(1-3):257-281

Vicuña S, Dracup JA, Dale L (2009) Climate change impacts on the operation of two high elevation hydropower systems in California. California climate change center, CEC-500-2009-019D. http://www.energy.ca.gov/2009publications/CEC-500-2009-019/CEC-500--2009-019-D.PDF. Accessed March 2009

Vicuña S, Leonardson R, Hanemann MW, Dale LL, Dracup JA (2008) Climate change impacts on high elevation hydropower generation in California's Sierra Nevada: a case study in the upper american river. Clim Change 28(Supplement 1):123-137

Zhu T, Jenkins MW, Lund JR (2005) Estimated impacts of climate warming on California water availability under twelve future climate scenarios. J Water Resour Plan Manage (JAWRA) 41(5):1027-1038 